\title{
COLEÇÕES VISITÁVEIS:
}

\author{
RELATO DE EXPERIÊNCIA ENTRE AS PRÁTICAS \\ DE ENSINO SOBRE DOCUMENTAÇÃO EM MUSEUS E \\ DE PESQUISA PARA A GESTÃO NA UNIRIO
}

ELIZABETE DE CASTRO MENDONÇA, UNIVERSIDADE FEDERAL DO ESTADO DO RIO DE JANEIRO, RIO DE JANEIRO, RIO DE JANEIRO, BRASIL

Graduada em Museologia e doutora em Artes Visuais pela Universidade Federal do Rio de Janeiro (UNIRIO). Professora do Departamento de Estudos e Processos Museológicos (UNIRIO) e do Programa de Pós-Graduação em Museologia e Patrimônio (PPGPMUS/UNIRIO e Museu de Astronomia e Ciências Afins). Coordenadora do Núcleo Multidimensional de Gestão do Patrimônio e de Documentação em Museus (NUGEP) e líder do Grupo de Estudo e Pesquisa em Museologia, Conhecimentos Tradicionais e Ação Social (GEMCTAS), ambos vinculados à UNIRIO.

E-mail: elizabete.mendonca@unirio.br

ORCID: https://orcid.org/0000-0003-4913-1872

JADDY NASCIMENTO PAROVSZKY GOMES DE SOUSA, UNIVERSIDADE FEDERAL DO ESTADO DO RIO DE JANEIRO, RIO DE JANEIRO, RIO DE JANEIRO, BRASIL

Graduada em Museologia pela Universidade Federal do Estado do Rio de Janeiro. Atualmente, é prestadora de serviço do Museu de Imagens do Inconsciente. Membro do Núcleo Multidimensional de Gestão do Patrimônio e de Documentação em Museus (NUGEP) e do Grupo de Estudo e Pesquisa em Museologia, Conhecimentos Tradicionais e Ação Social (GEMCTAS), ambos vinculados à UNIRIO.

E-mail: jaddyparovszky@outlook.com

ORCID: https://orcid.org/0000-0003-3965-1938

RECEBIDO

DOI

29/07/2020

APROVADO

http://dx.doi.org/10.11606/issn.1980-4466.v15i30p375-398

$26 / 11 / 2020$ 


\section{COLEÇÕES VISITÁVEIS: RELATO DE EXPERIÊNCIA ENTRE AS PRÁTICAS DE ENSINO SOBRE DOCUMENTAÇÃO EM MUSEUS E DE PESQUISA PARA A GESTÃO NA UNIRIO \\ ELIZABETE DE CASTRO MENDONÇA, JADDY NASCIMENTO PAROVSZKY GOMES DE SOUSA}

\section{RESUMO}

Este artigo apresenta resultados parciais do projeto de ensino "Gestão de coleções: análise sobre documentação de objetos associados aos conhecimentos tradicionais populares sob tutela da UNIRIO e aplicabilidade do sistema In Arte", vinculado ao Núcleo Multidimensional de Gestão do Patrimônio e de Documentação em Museus (NUGEP/UNIRIO), tendo como problemática a qualificação de informações sobre as coleções universitárias. Seu objetivo é explicitar o processo de documentação e qualificação de dados das coleções visitáveis da UNIRIO a partir da experiência entre as práticas de ensino de documentação museológica e de pesquisa para a gestão das coleções, tendo como foco o acervo da Biblioteca Central - especialmente os objetos que pertenceram ao professor Pernambuco de Oliveira, que hoje integram a Coleção de Artesanato e Arte Popular. O trabalho inicial de documentação do acervo foi realizado a partir da revisão do inventário e consequente quantificação do acervo. Desde 2018, a coleção é catalogada pelos discentes da disciplina Informação e Documentação Museológica I, do curso de graduação em Museologia, no sistema de gestão de coleções In Arte Online. As ações acadêmicas de catalogação, potencializadas pelo uso do software de gestão de coleções, contribuem para a formação teórico-prática dos futuros profissionais de museologia e promovem o reconhecimento e a identificação das coleções da própria universidade, podendo auxiliar na definição de diretrizes sobre políticas de gestão dos seus bens culturais.

\section{PALAVRAS-CHAVE}

Documentação museológica, Acervo museológico, Gestão de bens culturais, Cultura popular. 


\section{VISITABLE COLLECTIONS: EXPERIENCE REPORT OF THE TEACHING PRACTICE ABOUT DOCUMENTATION IN MUSEUMS AND THE RESEARCH FOR MANAGEMENT OF COLLECTIONS AT UNIRIO}

ELIZABETE DE CASTRO MENDONÇA, JADDY NASCIMENTO PAROVSZKY GOMES DE SOUSA

\section{ABSTRACT}

This paper presents partial results of the teaching project called "Gestão de coleções: análise sobre documentação de objetos associados aos conhecimentos tradicionais populares sob tutela da UNIRIO e aplicabilidade do sistema In Arte" (Collections Management: Analysis of the Documentation of Objects Associated with Popular Traditional Knowledge and Applicability of In Arte System), developed at the Núcleo Multidimensional de Gestão do Patrimônio e de Documentação em Museus (NUGEP/UNIRIO). The present paper focuses on the qualification of informations about university collections, aiming to describe the process of documentation and qualification of data pertaining to visitable collections under the guardianship of UNIRIO, based on the experiences with museological documentation teaching and the research about collections management, with a focus on the collection maintained by the Central Library - specifically the objects that once belonged to Professor Pernambuco de Oliveira and now are part of the Coleção de Artesanato e Arte Popular (Crafts and Popular Art Collection). The initial work of collection documentation started with the review of the inventory, followed by the quantification of the collection. Since 2018, the collection has been cataloged by the students in the "Information and Museological Documentation I" course at the undergraduate program in Museums Studies, using the system of collections management called In Arte Online. Academic cataloging activities, enhanced by the use of collection management software, contribute to the theoretical/practical training of future museology professionals and promote the recognition and identification of the university's own collections, thus enabling the definition of guidelines on policies for the management of its cultural assets.

\section{KEYWORDS}

Museum documentation, Collection, Management of cultural assets, Popular culture. 


\section{INTRODUÇÃO}

Segundo Clifford (1994, p. 71), os sistemas de colecionismo, "sempre poderosos e governados pelas normas [classificatórias], mudam historicamente", transformando-se em uma prática social que expressa situações relativas à produção, circulação e consumo de objetos, atribuindo-lhes valores e construindo narrativas que refletem normas culturais. Pode-se dizer, portanto, que a formação e a classificação ${ }^{1}$ de uma coleção expressam tanto as relações entre os objetos e os diferentes grupos sociais quanto os modos como uma instituição de memória constrói ideias e valores.

As universidades não fogem a essa prática social. A formação de coleções em universidades remonta à Biblioteca de Alexandria, na qual é possível identificar tanto características de universidade como de museu.

Aquele recinto onde artistas, poetas e sábios confraternizavam em uma espécie de cooperação intelectual, contava com um observatório, salas de reunião, jardins zoológicos e botânicos e, sobretudo, com a famosa

\footnotetext{
1. O ato de classificar, segundo Gonçalves (2007), é uma prática universal que nomeia, divide e hierarquiza as coisas a partir da maneira como são percebidas pelos diferentes grupos sociais. Esta prática rotineira é geralmente naturalizada, vista como algo dado, e não como um processo de construção social que expressa o modo como as sociedades se organizam e dão sentido à vida coletiva. No entanto, semelhante ao que ocorre na vida cotidiana, as práticas classificatórias construídas para selecionar, nomear, ordenar e catalogar objetos que compõem coleções (bibliográficas, arquivísticas e museológicas) expressam o modo como as instituições constroem memórias e narrativas.
} 
biblioteca onde se guardavam cerca de oitocentos manuscritos. Era, sem dúvida, uma espécie de cidade universitária que não só dava importância ao cultivo do intelecto, visto que a natureza era considerada um elemento indispensável para a formação humana (FERNÁNDEZ, 1993, p. 57 apud ALMEIDA, 2001, p. 12, tradução nossa)².

De acordo com as palavras de Lourenço (2005), a presença de gabinetes de curiosidades nas instituições universitárias da Europa, a partir do século XVII, mudou a forma de se fazer ciência, pois não eram mais apenas espaços classificatórios dos seres da natureza, mas sim espaços de experimentação e observação. É a partir do ensino e da pesquisa, principalmente no século XIX e no início do século XX, que surgem as primeiras coleções universitárias, visto que o ensino era baseado no estudo de espécimes de diferentes naturezas. No Brasil, a origem das universidades remonta ao período imperial, e a maioria dos museus universitários surge ou simultaneamente, com a criação destas, ou posteriormente, a partir de coleções formadas por pesquisas universitárias ou doações (ALMEIDA, 2001, p. 51). Porém, em um cenário não limitado aos museus universitários, o processo de documentação efetiva das coleções ainda se encontra aquém do desejável, uma vez que privilegia as informações intrínsecas em detrimento das informações extrínsecas ${ }^{3}$, que perpassam a trajetória, o histórico e a vida social ${ }^{4}$ dos objetos.

2. "Aquel recinto donde fraternizaban artistas, poetas y sabios en una especie de cooperación intelectual, contaba con un observatorio, salas de reunión, laboratorios, jardines zoológicos y botánicos y, sobre todo, con la famosa biblioteca en la que se guardaban unos ochocientos mil manuscritos. Era, sin duda, una especie de ciudad universitaria que no sólo concedía importancia al cultivo del intelecto, ya que la naturaleza era considerada como elemento indispensable para la formación humana." (FERNÁNDEZ, 1957, p. 57 apud ALMEIDA, 2001, p. 12)

3. De acordo com Ferrez (1991), as informações intrínsecas são aquelas contidas no próprio objeto, geralmente relacionadas a elementos possíveis de detectar a partir da observação visual. Compreendem a estrutura física dos objetos, como material, técnica, dimensão, cor, forma. Por sua vez, as informações extrínsecas estão relacionadas ao contexto histórico e simbólico ao qual o objeto pertence. Abrangem a função e o significado do objeto, além de sua trajetória histórica. 4. Reflexão sugerida por Appadurai (2008) e Kopytoff (2008) que recai na percepção de que as coisas ou objetos também são possuidores de uma vida social e que, assim como as pessoas, está associado a uma biografia cultural e social. Um objeto, ao ser musealizado, continua tendo uma trajetória dentro da instituição. Portanto, ele possui uma trajetória anterior e posterior a ser categorizado como objeto museal, neste sentido, como uma biografia social e cultural. 
Não distante de tais parâmetros, a coleção da Universidade Federal do Estado do Rio de Janeiro (UNIRIO) abordada neste artigo 5 também está relacionada à perspectiva de formação pela e para pesquisa, além de auxiliar o ensino universitário. Nesse sentido, com base na formação das coleções da UNIRIO e no olhar museológico sobre essas coleções, este artigo busca explicitar o processo de documentação e qualificação dos dados sobre as coleções visitáveis da UNIRIO a partir da experiência entre as práticas atuais de ensino sobre documentação e de pesquisa para a gestão de coleções, realizadas no âmbito do Núcleo Multidimensional de Gestão do Patrimônio e de Documentação em Museus (NUGEP/UNIRIO), vinculado ao ensino e à pós-graduação em Museologia desta universidade. Para tal reflexão, foram selecionados objetos que pertenceram ao professor Pernambuco de Oliveira e que hoje integram a coleção de artesanato e arte popular da Biblioteca Central da UNIRIO.

A pertinência dessa análise se justifica pela relevância da qualificação dos dados relativos a essa coleção no processo de documentação, para que a instituição possa cumprir, cada vez mais, seu papel na preservação e disseminação da informação para geração de conhecimento, potencializando assim sua função social.

5. Este artigo apresenta resultados parciais do projeto de ensino "Gestão de coleções: análise sobre documentação de objetos associados aos conhecimentos tradicionais populares sob tutela da UNIRIO e aplicabilidade do sistema In Arte" e do trabalho de conclusão de curso de autoria da discente Jaddy Parovszky, intitulado "Documentação e Sistemas de informação: práticas de documentação e de pesquisa para a gestão de coleções visitáveis associadas aos conhecimentos tradicionais populares da UNIRIO”, ambos vinculados ao Núcleo Multidimensional de Gestão do Patrimônio e de Documentação em Museus (NUGEP/UNIRIO). Entre março e dezembro de 2018, o projeto de ensino contou com uma equipe formada pela professora Elizabete de Castro Mendonça (coordenadora) e dois bolsistas, a saber: Ariane Corrêa Silvestre da Silva e Luiz Felipe da Silva Santana. A partir de agosto de 2018, passaram a integrar a equipe três voluntárias, a saber: Jaddy Nascimento Parovszky Gomes de Sousa, Sofia Duarte Girard de Oliveira e Thaysi Amaral Soares. As duas primeiras tornam-se bolsistas a partir de fevereiro de 2019 e ainda permanecem na equipe no ano de 2020. A partir de fevereiro 2019, também passou a integrar a equipe uma voluntária que permanece em 2020, a saber: Danca Aparecida da Silva Mesquita. No segundo semestre de 2019, integram a equipe mais três bolsistas voluntários: Alice Quintella Tischer, Talita Ferreira de Souza e Yuri Costa Pinto Mariano (este último permanece na equipe em 2020). Em março de 2020, junta-se à equipe a voluntária Joyce Mendes Gomes Barros e a estagiária curricular Clarissa Ribeiro de Souza. Atualmente, a equipe conta com quatro monitores, sendo dois bolsistas, dois voluntários e uma estagiária curricular. Ao longo desses anos, o projeto também contou com estagiários à docência, a saber: Paulo Victor Catharino Gitsin (2018-2020), Heide Roviene Santana dos Santos (2019) e Mariana Silva Santana (2018), além das bibliotecárias Bárbara Alessandra Ribeiro de Miranda Lima (2018-2020), Maria Marta Magno Calheiros (2018-2020) e da arquivista Paulina Aparecida Marques Vieira Albuquerque (2019). Os primeiros integrantes são estudantes do curso de graduação em Museologia; os estagiários à docência são mestrandos e doutorandos do PPG-PMUS; e os últimos são técnicos da UNIRIO. 
Para a compreensão da dinâmica utilizada neste artigo, fez-se necessário conceituar e contextualizar a relação entre museus universitários ${ }^{6}$ e coleções universitárias, para, em seguida, relatar a experiência de reconhecimento, identificação, registro, documentação e gestão das coleções visitáveis da UNIRIO a partir das práticas de ensino, refletindo sobre os desafios e as perspectivas futuras.

\section{A UNIRIO E SUAS COLEÇÕES VISITÁVEIS}

A UNIRIO responde pelo curso de graduação em Museologia mais antigo do país. Oriundo do Curso de Museus, vinculado ao Museu Histórico Nacional (MHN), foi criado em 1932 e transferido, em 1979, de uma instituição de memória (MHN) para uma instituição de ensino, a Federação das Escolas Federais Isoladas do Rio de Janeiro (FEFIERJ), atual UNIRIO (TANUS, 2013). Apesar desse histórico como instituição de ensino ligada à formação acadêmica do pensamento museológico brasileiro, a UNIRIO não possui em sua estrutura organizacional um museu. Contudo, no levantamento realizado por Novaes (2018), foram identificadas 46 coleções sob sua guarda (incluindo os grupos de objetos com potencial para formar uma coleção), sendo que 50\% concentram-se no Centro de Ciências Biológicas, $37 \%$ no Centro de Letras e Artes, $11 \%$ na Biblioteca Central e $2 \%$ no Centro de Ciências Humanas e Sociais.

Esse processo de formação de coleções em universidades não é exclusivo da UNIRIO. Assim como outras universidades brasileiras, grande parte de suas coleções é constituída a partir de doações e de práticas de ensino e pesquisa de várias de suas unidades organizacionais.

O enquadramento desses conjuntos de objetos como coleções é relevante, porque, conforme sugere Almeida (2001), existem definições diferenciadas para os conceitos de museu universitário e coleção universitária. Para a autora, os museus universitários e as coleções universitárias são "unidades da universidade que adquirem, conservam e pesquisam com fins de estudo, educação e apreciação" (ALMEIDA, 2001, p. 31), tendo como principal distinção entre as duas definições a

6. Para mais informações sobre museus e patrimônio universitários, ver Gil (2005), Mendonça (2014) e Ribeiro et al. (2019). 
questão comunicativa das coleções. A primeira exibe parte ou toda a sua coleção em um espaço específico para isso (o espaço do museu), enquanto a segunda é exposta de forma limitada, podendo estar em diferentes unidades da universidade.

O conceito de museu universitário de Almeida (2001) é claramente baseado no conceito de museu do Conselho Internacional de Museus (Icom)7. A definição do Icom também é apropriada pelos autores Desvallés e Mairesse (2013), porém, estes ainda nos brindam com a colocação de que o museu "tanto pode designar a instituição quanto o estabelecimento, ou o lugar geralmente concebido para realizar a seleção, o estudo e a apresentação de testemunhos materiais e imateriais do Homem e do seu meio" (DESVALLÉS; MAIRESSE, 2013, p. 64), ampliando ainda mais o olhar sobre o que pode ser contemplado nessa perspectiva conceitual de instituição. Na mesma publicação, os autores definem coleção como

$$
\begin{aligned}
& \text { conjunto de objetos materiais ou imateriais que um indivíduo, ou } \\
& \text { um estabelecimento, se responsabilizou por reunir, classificar, se- } \\
& \text { lecionar e conservar em um contexto seguro e que, com frequência, } \\
& \text { é comunicada a um público mais ou menos vasto, seja esta uma } \\
& \text { coleção pública ou privada. Para se constituir uma verdadeira co- } \\
& \text { leção, é necessário que esses agrupamentos de objetos formem um } \\
& \text { conjunto (relativamente) coerente e significativo [...] (DESVALLÉS; } \\
& \text { MAIRESSE, 2013, p. 32). }
\end{aligned}
$$

Além disso, o Decreto Federal no 8.124 (BRASIL, 2013) ${ }^{8}$ também conceitua coleções visitáveis em seu artigo $2^{\circ}$, inciso V: "conjuntos de bens culturais conservados por pessoa física ou jurídica que não apresentem as características previstas nos incisos IX e X do caput, e que sejam abertos à visitação;

7. "A museum is a non-profit, permanent institution in the service of society and its development, open to the public, which acquires, conserves, researches, communicates and exhibits the tangible and intangible heritage of humanity and its environment for the purposes of education, study and enjoyment." (INTERNATIONAL COUNCIL OF MUSEUMS, 2007).

8. Decreto Federal no 8.124, de 17 de outubro de 2013. Regulamenta dispositivos da Lei no 11.904 , de 14 de janeiro de 2009, que institui o Estatuto de Museus, e da Lei no 11.906, de 20 de janeiro de 2009, que cria o Instituto Brasileiro de Museus - IBRAM. 
ainda que esporadicamente"s.

Com base em dados levantados e analisados na presente pesquisa, e confrontando-os com as definições apresentadas acima sobre os conceitos de coleção, coleção visitável e museu, compreende-se que a UNIRIO tem coleções formadas a partir de coleta ou doação, principalmente de professores, em diversas unidades organizacionais que a compõem. Essas coleções são conservadas, pesquisadas e expostas (permanente ou esporadicamente) e têm como público-alvo a comunidade acadêmica (estudantes, professores e técnicos). Portanto, caracterizam-se como coleções visitáveis.

Em meio a esse contexto reflexivo sobre o perfil das coleções da UNIRIO no âmbito do projeto de ensino "Gestão de coleções: análise sobre documentação de objetos associados aos conhecimentos tradicionais populares sob tutela da Unirio e aplicabilidade do sistema In Arte"10, aplicado à disciplina obrigatória Informação e Documentação Museológica I do curso de graduação em Museologia da UNIRIO, coleções visitáveis de unidades organizacionais da universidade ${ }^{11}$ foram priorizadas para as ações de

9. Os incisos IX e X definem o conceito de museu e processo museológico:

"IX - museu - instituição sem fins lucrativos, de natureza cultural, que conserva, investiga, comunica, interpreta e expõe, para fins de preservação, estudo, pesquisa, educação, contemplação e turismo, conjunto e coleções de valor histórico, artístico, científico, técnico, ou de outra natureza cultural, abertos ao público, a serviço da sociedade e de seu desenvolvimento.

$\mathrm{X}$ - processo museológico - programa, projeto e ação em desenvolvimento ou desenvolvido com fundamentos teórico e prático da museologia, que considere o território, o patrimônio cultural e a memória social de comunidades específicas, para produzir conhecimento e desenvolvimento cultural e socioeconômico."

10. Apesar de este projeto ter como objetivo central a capacitação prática dos alunos inscritos na disciplina em ferramenta de gestão de coleções, mais especificamente, no sistema de gestão de coleções In Arte Online, ele contribui também para maior (re)conhecimento das coleções sob tutela da instituição. No que cabe à ação de ensino, vale ressaltar que o uso do software, bem como sua hospedagem e acesso na cloud, só foi possível devido ao estabelecimento de um Acordo de Cooperação Técnica entre a UNIRIO e a empresa portuguesa Sistemas do Futuro, Multimídia, Gestão e Arte LTDA (SF), intermediado pelo Grupo de Estudo e Pesquisas em Museologia, Conhecimentos Tradicionais e Ação Social (GEMCTAS) vinculado ao NUGEP/UNIRIO, acordo este em que o sistema foi cedido de forma gratuita em 2016 para capacitação dos alunos. A opção por este sistema informatizado se deve ao fato de ser um sistema desenvolvido especificamente para coleções museológicas e ter base em diretrizes/normas estabelecidas por instituições como o Comitê Internacional de Documentação do Conselho Internacional de Museus (CIDOC/Icom), a Collections Trust, o Getty Research Institute, a Canadian Heritage Information Network e a Organização das Nações Unidas para a Educação, a Ciência e a Cultura (UNESCO). Ou seja, por estar enquadrado nos parâmetros internacionais de documentação reconhecidos.

11. Para a primeira etapa de catalogação, foram estabelecidas parcerias com o Núcleo de Memória da Museologia no Brasil (NUMMUS), vinculado à Escola de Museologia, e com a Biblioteca Central da UNIRIO. Na segunda etapa, a parceria foi ampliada para o Núcleo de Estudos das Performances Afro-Ameríndias (NEPAA), vinculado à Escola de Teatro. 
identificação, registro e catalogação. No que se refere à tipologia de coleção, foram priorizados os objetos associados a conhecimentos tradicionais e cultura popular. Essa escolha foi intencional, a fim de promover futuras articulações entre os três eixos das ações universitárias (ensino, pesquisa e extensão) desenvolvidos no NUGEP ${ }^{12}$ pelo Grupo de Estudos e Pesquisas em Museologia, Conhecimentos Tradicionais e Ação Social (GEMCTAS). Cabe lembrar que, para este artigo, foram selecionados objetos que pertenceram ao professor Pernambuco de Oliveira e que hoje integram a Coleção de Artesanato e Arte Popular da Biblioteca Central da UNIRIO.

\section{COLEÇÃO DE ARTESANATO E ARTE POPULAR DA BIBLIOTECA CENTRAL: DA DIDÁTICA SOBRE CENOGRAFIA A BEM CULTURAL}

A Biblioteca Central da UNIRIO foi criada em 1976, quando a universidade era denominada FEFIERJ, e é uma das unidades organizacionais que tem a guarda de coleções. Conforme explicitado no site da instituição:

A origem do Acervo Especial das bibliotecas da UNIRIO é muito próxima à da maioria das instituições públicas do Brasil: diversificada, reflexo de uma política cultural com interrupções e descontinuidades, apresentando de tudo um pouco. Possuímos acervos característicos das áreas de arquivos pessoais, bibliotecas e museus dispersos pelas diversas bibliotecas do Sistema. (BIBLIOTECA CENTRAL - UNIRIO, [s.d.])

Além disso, na mesma página, são apresentadas as coleções do acervo da Biblioteca Central, destacando-se o seguinte trecho:

\footnotetext{
Como objetos museológicos (museália), a Biblioteca possui alguns instrumentos musicais de beleza ímpar, além de uma coleção de máscaras rituais, teatrais e artísticas de diversas procedências; uma coleção de objetos de artesanato e arte popular de diversas regiões brasileiras; uma coleção de pôsteres de peças teatrais de Guilherme Figueiredo; fotos, gravuras francesas; e algumas telas de artistas nacionais e estrangeiros. Algumas dessas obras estão em exposição permanente na Biblioteca Central (BIBLIOTECA CENTRAL - UNIRIO, [s.d.]).
}

O foco deste artigo é a coleção de artesanato e arte popular desta biblioteca, tendo como panorama das práticas museológicas os processos de

12. Para maiores informações sobre o NUGEP, ver: http://www.unirio.br/nugep e http://www. nugepunirio.org. 
documentação e de gestão de coleções ${ }^{13}$. Para uma documentação e gestão eficaz das coleções, seguindo o que preconizam autores como Ferrez (1991), Lima (2010) e Loureiro (2013), no ato de documentar prioriza-se o conjunto de informações intrínsecas e extrínsecas sobre cada um dos itens, bem como a representação destes por meio de palavras e recursos audiovisuais. Dessa forma, enfatiza-se o relacionamento dos objetos com eventos e entidades, com o objetivo de obter uma organização e normalização dos dados em um sistema que permita a recuperação de informação. Compreende-se, portanto, que as ações de documentação estão interligadas a outras ações do processo de musealização ${ }^{14}$ de um bem cultural $^{15}$ e são a base para a transformação de "coleções dos museus de fontes de informações em fontes de pesquisa científica: em instrumentos de transmissão de conhecimento" (FERREZ, 1991, p. 1). De acordo com Ceravolo e Tálamo (2007, p. 5), entende-se documentação como “[...] uma série de procedimentos técnicos para salvaguardar e gerenciar as coleções sob guarda dos museus".

Além disso, atualmente, a documentação museológica é compreendida em um sentido mais amplo, de forma integrada à gestão de coleções, e definida por autoras como Semedo (2005) e Augustin e Barbosa (2018) como políticas e procedimentos que estão relacionados à aquisição, inventário, catalogação, controle, utilização, empréstimo, alienação, exposições e transporte das coleções. Ou seja, conforme mencionado, a gestão de coleções e documentação museológica perpassa diversos aspectos que visam à preservação das coleções (seleção, aquisição, documentação, pesquisa, conservação e comunicação).

A parceria entre NUGEP e Biblioteca Central para que os objetos sob a guarda desta última fossem incluídos no projeto de ensino coordenado pelo

13. De acordo com Cidoc (2014, p. 42), a documentação caracteriza-se pelos "Registros que documentam a criação, a história, a aquisição feita pelo museu e a história subsequente de todos os objetos do acervo. Esses registros incluem documentos de origem e procedência, documentos de aquisição, relatórios de conservação, fichas de catalogação, imagens e pesquisas criados tanto pela instituição detentora do objeto, como por proprietários anteriores, pesquisadores independentes etc. O termo também se aplica ao processo de coleta dessas informações." O mesmo documento define a gestão de coleções como a "Garantia de uma documentação, preservação e acesso eficientes às coleções museológicas". 14. Neste artigo, entende-se a musealização como um processo científico que abarca um conjunto de procedimentos vinculados à seleção, aquisição, pesquisa, conservação, documentação e comunicação e tem o objetivo de atribuir ao objeto função de documento (DESVALLÉES; MAIRESSE, 2013). 15. Segundo Souza Filho (2005, p. 36), bem cultural é "aquele bem jurídico que, além de ser objeto de direito, está protegido por ser representativo, evocativo ou identificador de uma expressão cultural relevante". 
NUGEP foi firmada em 2018. Tendo em vista a importância da normalização ${ }^{16}$ para a documentação e gestão das coleções, neste momento, de acordo com a proposta do projeto e o perfil do componente curricular a ele vinculado, a equipe definiu, com base em padrões e recomendações nacionais e internacionais $^{17}$ que visam auxiliar nos desafios da prática museológica e compatibilizar os registros dos objetos, focar nos conjuntos de políticas, processos e procedimentos relativos a controle de inventário, controle de localização e de movimentação, catalogação e documentação retrospectiva, conforme apresentado no diagrama da Figura 1, que apresenta os procedimentos de Informação sobre as Coleções (Documentação) da norma Spectrum.

A primeira tarefa levantada foi iniciar a revisão do inventário do acervo, devido à necessidade de identificar e compreender a quantidade de objetos presentes no acervo da Biblioteca Central como um todo e sua localização exata. Esse trabalho contou com três voluntárias ${ }^{18}$ discentes da graduação e teve duração de seis meses. Alguns objetos possuíam uma ficha de inventário em papel ${ }^{19}$, cujo preenchimento, em geral, se limitava a informações intrínsecas básicas, com muitas lacunas informacionais ${ }^{20}$. Outros objetos sequer possuíam essa ficha ${ }^{21}$.

16. Como debate Matos (2010), a normalização é um conjunto de procedimentos adotados pelos museus a fim de gerir de forma eficaz suas coleções. Para o autor, existem três tipos de normas importantes para os museus: "normas de estrutura de dados, as de procedimento e as normas relativas aos conteúdos e linguagem utilizada, mais conhecidas como thesauri ou listagens terminológicas" (MATOS, 2010, p. 30). Todas essas normas se relacionam entre si.

17 Para as normas de procedimento utiliza-se a norma Spectrum: padrão para gestão de coleções de museus do Reino Unido, lançada em 1994 e traduzida para o português em 2011, considerada uma referência internacional sobre procedimentos a serem adotados no cotidiano da gestão de coleções (COLLECTIONS TRUST, 2014). Sobre normas de estrutura de dados, utiliza-se a Declaração de princípios de documentação em museus e diretrizes internacionais de informação sobre objetos de museus: categorias de informação do Comitê Internacional de Documentação (CIDOC - Icom)" (INTERNATIONAL COUNCIL OF MUSEUMS, 2014), além do Introduction to Object ID: Guidelines for Making Records that Describe Art, Antiques and Antiquities (THORNES et al., 1999), importante ferramenta para o combate ao tráfico ilícito de bens culturais, e o Inventário Nacional de Bens Culturais Musealizados (INBCM) (BRASIL, 2014).

18. A saber: Danca Aparecida da Silva Mesquita, Sofia Duarte Girard de Oliveira e Thaysi Amaral Soares. 19 Com o auxílio de duas alunas do curso de Museologia, a Biblioteca padronizou no primeiro semestre do ano de 2018 uma nova ficha de catalogação. Contudo, as informações continuaram muito focadas nas informações intrínsecas aos objetos e com poucos campos preenchidos.

20. Lima (2010) define a expressão "lacunas informacionais" como ausência ou dúvidas acerca dos dados registrados nos campos de informação das fichas catalográficas.

21. Um quadro muito comum no processo de documentação de diversas instituições. 


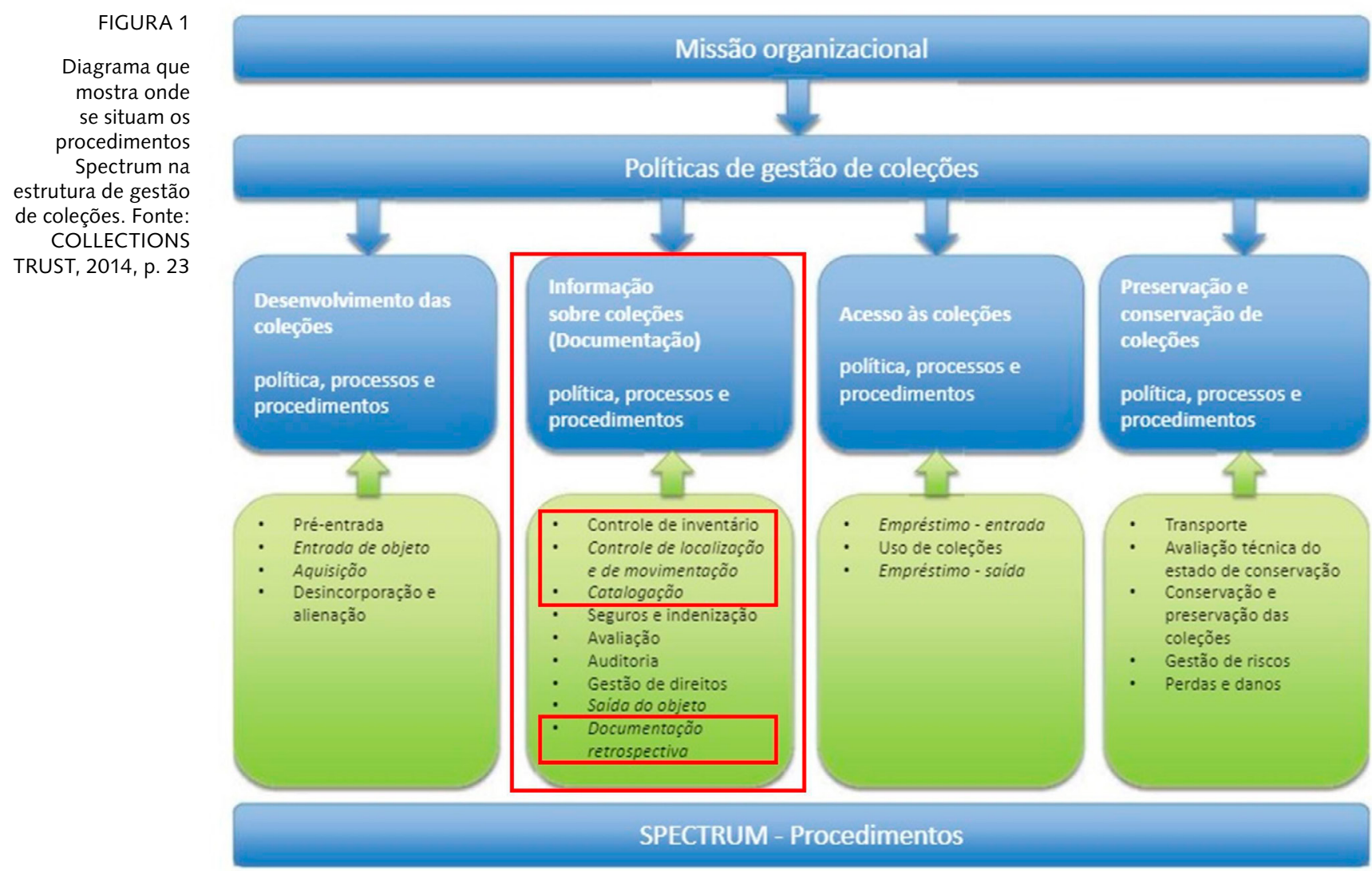

FIGURA 2

Fichas de inventário

de dois objetos da

Biblioteca Central.

Fonte: Biblioteca

Central da UNIRIO. 
O trabalho começou com a identificação de quais objetos tinham ficha catalográfica e quais não, passando em seguida à localização dos objetos e digitalização das fichas. Com isso, foi gerada uma planilha com as seguintes informações: fotografia ${ }^{22}$, número de inventário, título, autor e localização. Nesse processo, foram consideradas relevantes todas as ações pretéritas de inventário ou catalogação dos objetos, entendendo que a documentação retrospectiva oferece elementos para análise e compreensão das narrativas construídas pela instituição sobre os objetos e sobre sua própria história. Com base nessa premissa, todas as fichas foram digitalizadas e serão disponibilizadas no atual processo de catalogação.

FIGURA 3

Planilhas de inventário do acervo da Biblioteca Central.

Fonte: NUGEP/ UNIRIO

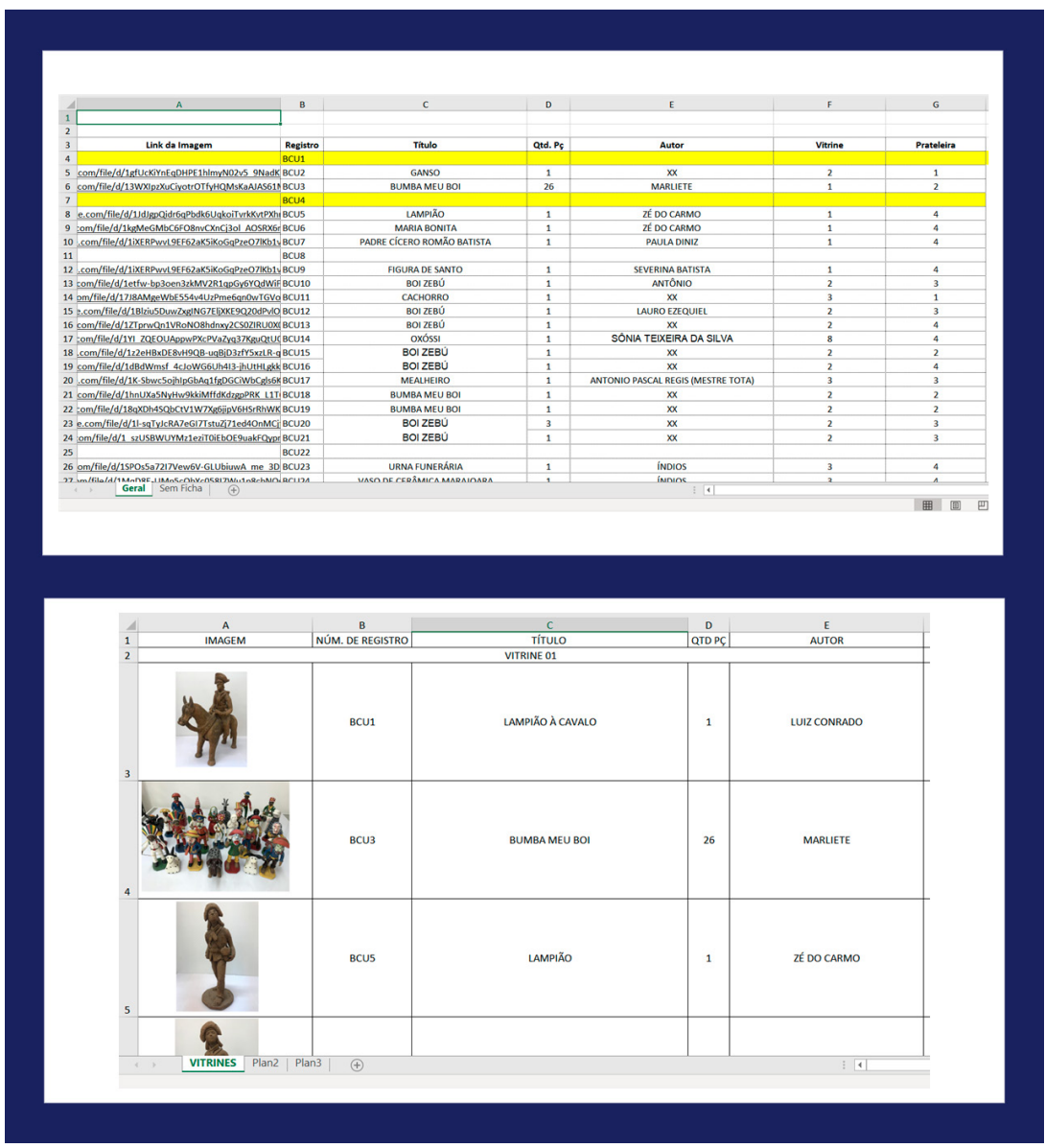

22. Apenas uma fotografia para identificação utilizando aparelho celular. A fotografia dentro dos parâmetros de documentação de coleções para inserção no sistema In Arte é produzida durante a oficina "Fotografia para documentação em museus", ministrada todo semestre pelo museólogo Paulo Victor Catharino Gitsin, no âmbito da disciplina Informação e Documentação Museológica I, como parte do processo de catalogação com os discentes na disciplina. 
Nesse levantamento, foi possível verificar que o acervo da Biblioteca Central possui 584 objetos, sendo que 246 pertenceram ao professor Pernambuco de Oliveira. Por isso, o foco dos estudos e pesquisas tem sido nestes objetos. Além disso, todos os 41 objetos da Biblioteca Central catalogados no sistema In $\mathrm{Arte}^{23}$ pelos discentes durante as aulas práticas até $\mathrm{o}$ momento pertenceram a Pernambuco de Oliveira (Figura 4$)^{24}$.

FIGURA 4

Objetos da Coleção de Artesanato e Arte popular da Biblioteca Central da UNIRIO

Foto 1: Conjunto Maracatu - Zé Caboclo Filho [artista] I Foto: Johanna Kaltenecker. Foto 2: Ritxòkò - Karajá [grupo] I Foto: Marina de Castro Melo

Casimiro. Foto 3: Anjo

- Marliete Rodrigues da Silva [artista] I Conjunto Bumba-meu-boi I Foto: Gabriel Alonso Moraes e Priscila Julia de Almeida Fonte: NUGEP/UNIRIO

FIGURA 5

Visualização em plano geral do módulo catalogação do sistema In Arte

Online: imagem de acesso às fichas dos objetos da Biblioteca Central. Fonte: https://unirio. inarteonline.net/.
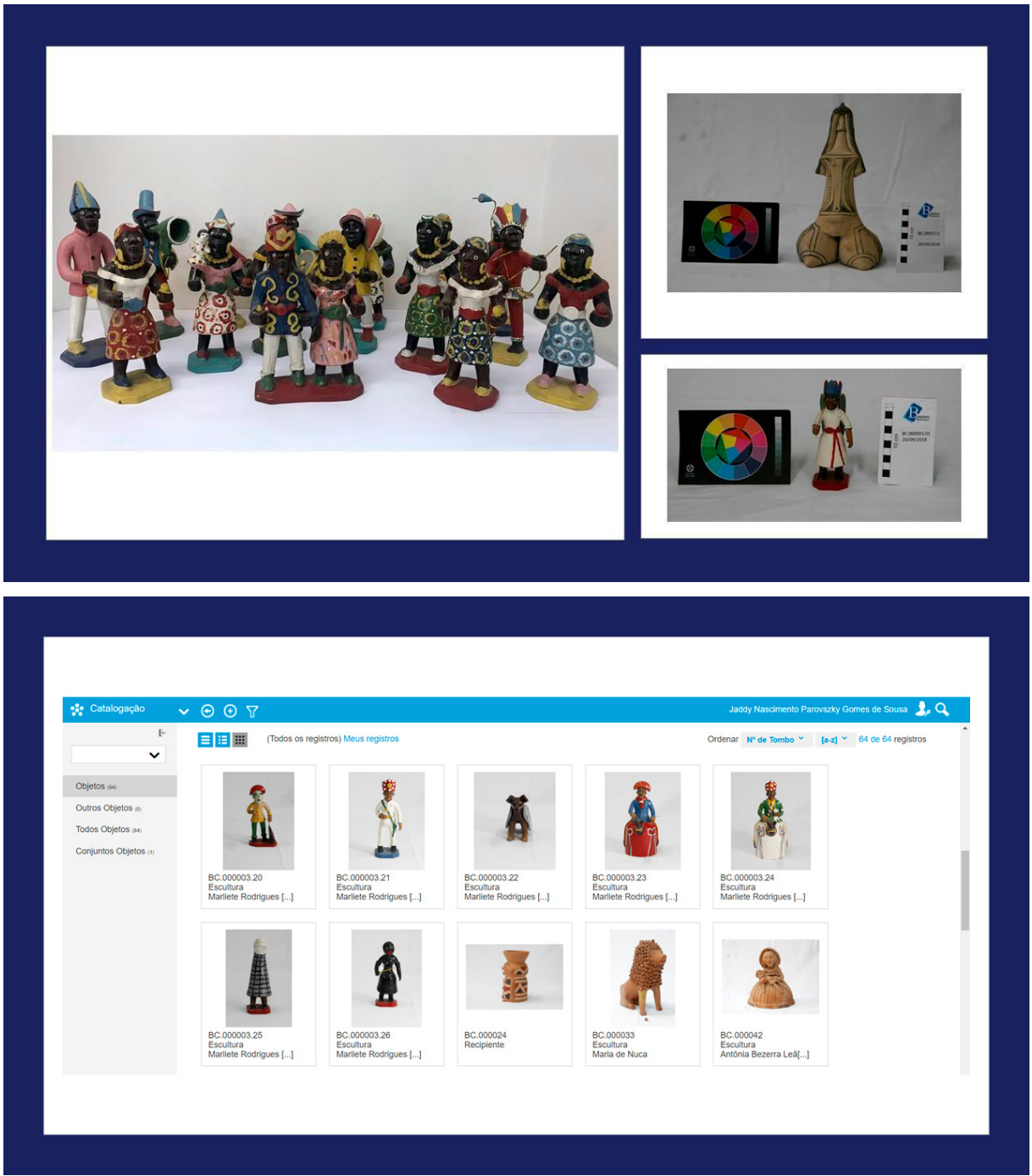

23. Devido ao perfil da coleção escolhida para a análise (representações da cultura popular brasileira), os objetos são catalogados de forma individual. No caso de objetos que pertençam a conjuntos, é feita a ficha catalográfica individual de cada objeto do conjunto e uma ficha do conjunto, na qual relaciona-se todos os objetos.

24. Conforme pode ser verificado na Foto 2, os objetos que pertenceram ao professor Pernambuco de Oliveira também contemplam objetos indígenas. 
Segundo a Enciclopédia Itaú Cultural de arte e cultura brasileira (PERNAMBUCO..., 2017), Pernambuco Gago Sacadura de Oliveira foi um cenógrafo, dramaturgo, figurinista, diretor de teatro e pioneiro na montagem de cenários de emissoras televisivas. Estudou pintura na Escola de Belas Artes, entrou para o ramo da cenografia como assistente e discípulo do cenógrafo alemão Edward Löeffler, depois se apresentou individualmente como cenógrafo em 1947, produzindo a Valsa das Esquinas. No mesmo ano, entrou para o Teatro do Estudante do Brasil (TEB). Participou do grupo que sediou o Teatro de Arena da Guanabara, no Largo da Carioca, em 1963. A partir de 1966, deu aulas de iluminação nos cursos do Conservatório Nacional de Teatro ${ }^{25}$. Tornou-se chefe do Departamento de Cenografia em 1969; diretor-geral da Escola de Teatro da Federação das Escolas Federais Isoladas do Estado da Guanabara (FEFIEG, transformada depois em UNIRIO) em 1973; e decano do Centro de Artes da FEFIERJ em 1979.

Com o falecimento de Pernambuco, em 1983, os objetos foram transferidos para a Biblioteca. Por meio de pesquisas e relatos coletados a partir do diálogo com antigos funcionários da universidade, foi possível descobrir que vários desses objetos estiveram presentes na exposição "Acervo de Pernambuco de Oliveira", realizada pelo Centro de Letras e Artes no ano de 1983, após seu falecimento.

FIGURA 6

Fotos dos objetos da Biblioteca Central na exposição "Acervo de Pernambuco de

Oliveira". Fonte: Biblioteca Central da UNIRIO.

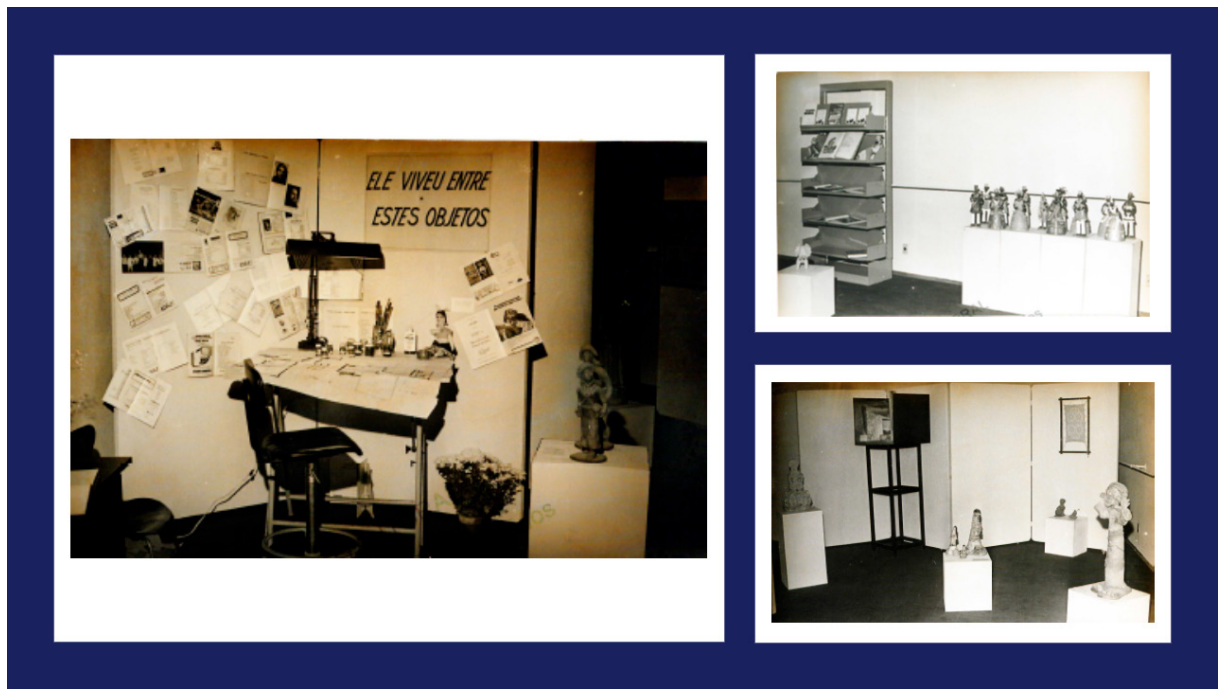

25. O Conservatório Nacional de Teatro (CNT) era vinculado ao Serviço Nacional de Teatro. Em 1969, com o surgimento da Federação das Escolas Federais Isoladas do Estado da Guanabara (FEFIEG), que posteriormente torna-se a FEFIERJ (1975), o CNT passa a ser denominado Escola de Teatro, desvinculando-se do Serviço Nacional de Teatro. 
A recuperação de dados sobre exposições, movimentações e o histórico da vida social do objeto é enfatizada durante o processo formativo dos alunos no âmbito da disciplina Informação e Documentação Museológica I do curso de Museologia. É estimulada a reflexão sobre possíveis fontes e instituições a serem consultadas ${ }^{26}$ para que o processo de documentação e gestão dessa coleção possa refletir ao menos três frentes de contexto às quais o objeto está relacionado, a saber: a história do contexto de produção do objeto; a história do colecionador (nesse caso, o professor Pernambuco de Oliveira) e a história da instituição (UNIRIO).

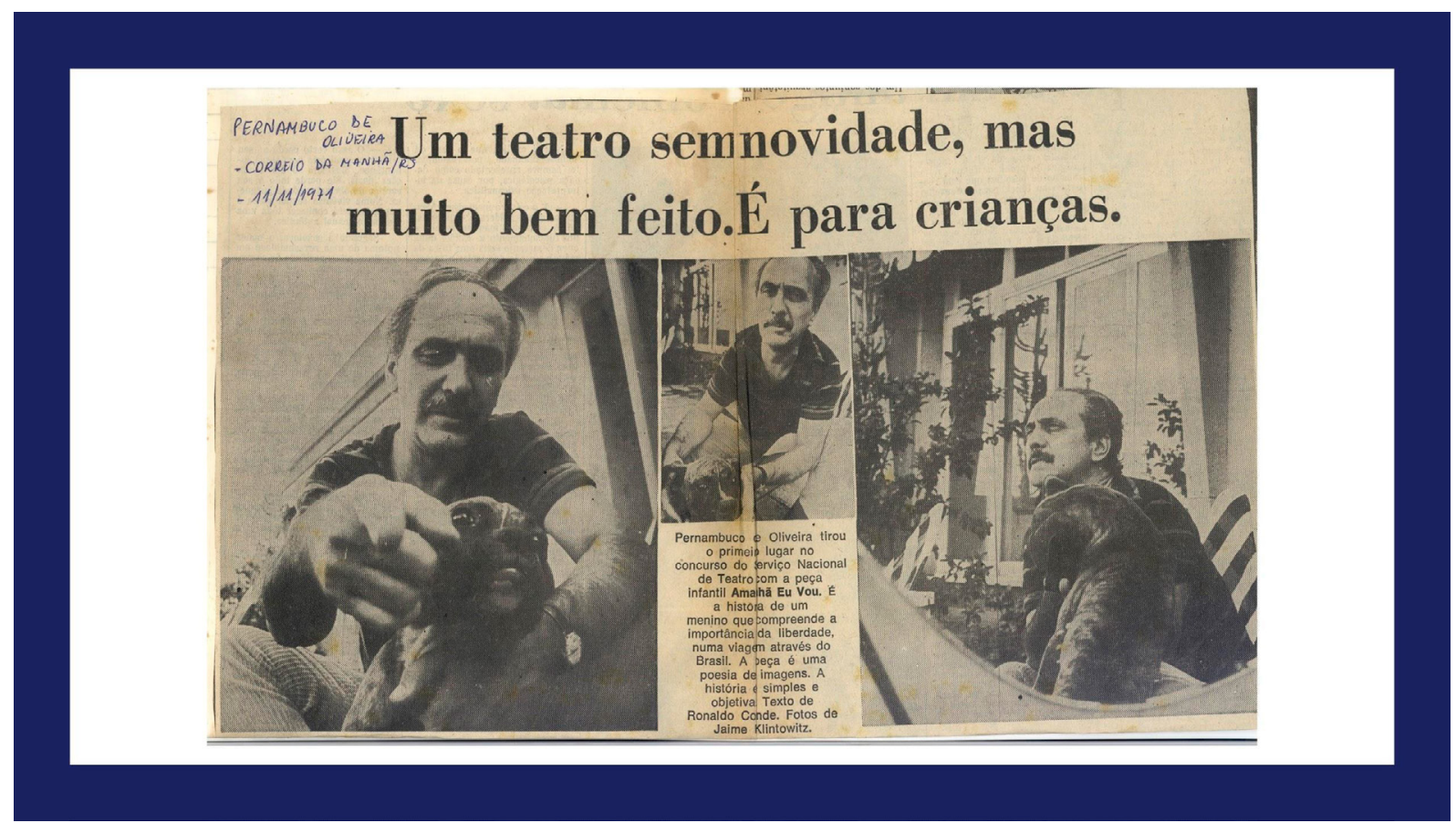

Recorte de jornal encontrado em consulta ao Dossiê de Pernambuco de Oliveira, no Centro de Documentação e Informação (Cedoc) da Funarte. Fonte: CEDOC/FUNARTE.

26. As fontes podem ser de origem bibliográfica, arquivística ou audiovisual, além de atentarem para a relevância das histórias orais, por meio do diálogo com professores e funcionários que trabalharam com Pernambuco de Oliveira ou sua coleção. A consulta e o diálogo com outras instituições também são estimulados a partir da ação conjunta realizada com o Museu de Folclore Edison Carneiro, do Centro Nacional de Folclore e Cultura Popular/Iphan, para que o processo de catalogação de dados sobre a produção do objeto seja mais bem qualificada. 
Importante destacar que as pesquisas sobre os objetos também contam com o apoio direto de duas bibliotecárias da universidade (Bárbara Alessandra Ribeiro de Miranda Lima e Maria Marta Magno Calheiros) e com a parceria do Centro Nacional de Folclore e Cultura Popular (CNFCP), por meio da Biblioteca Amadeu Amaral (BAA) e do Museu de Folclore Edison Carneiro (MFEC), que vêm, desde 2018, auxiliando tanto os alunos quanto a equipe do NUGEP na catalogação da coleção. O diálogo com o CNFCP é de suma importância para essas práticas, já que promove uma capacitação dos discentes que não se resume apenas ao conhecimento, mas também prevê a interação e colaboração entre equipes e o estabelecimento de redes de informação sobre os objetos, a fim de facilitar o processo de catalogação institucional.

Esse modelo de documentação e gestão da informação de forma integrada e cooperativa é citada por Serôdio (2018) como uma prática urgente que contribui para uma gestão mais eficiente dos acervos. Almeida afirma ainda que a colaboração

pode acontecer dentro de uma mesma instituição (ex. um museu que tenha arquivo e biblioteca), entre instituições que tenham uma estrutura administrativa comum (ex. museus subordinados a determinada esfera de governo), ou além de fronteiras institucionais (museus, bibliotecas, arquivos ou outras instituições que apresentem interesses e valores comuns). A gestão integrada é uma estratégia de colaboração que traz benefícios aos usuários, aos profissionais e enriquece a instituição. [...] Ganha aqui importância o desenvolvimento e uso de padrões de registro entre instituições semelhantes a fim de facilitar o intercâmbio (ALMEIDA, 2016, p. 180-181).

É nesse sentido que a documentação integrada e cooperativa entre NUGEP e CNFCP vem se desenvolvendo, com troca de saberes sobre os produtores dos objetos e suas áreas de produção, bem como sobre os sentidos locais dessa produção. Além dessas trocas, também existe um debate sobre terminologia, a fim de definir um vocabulário controlado comum para as duas instituições, fazendo com que algumas vezes o CNFCP reveja a catalogação de seus objetos.

Considerando que uma das etapas da aprendizagem dos discentes sobre o processo de pesquisa, documentação e gestão de coleções refere-se à catalogação no sistema In Arte, e que cada instituição deve formular 
seu próprio manual para normalização dos dados de entrada em sistemas de informação, foi elaborado um "Manual para Entrada de Dados no Sistema de Gestão do Patrimônio Cultural Móvel - In Arte Online (Módulo Catalogação)" ${ }^{\prime 27}$ para as coleções da UNIRIO.

Além disso, com base nas diretrizes e definições previstas no manual, são realizadas as revisões ${ }^{28}$ das informações inseridas nas fichas dos objetos catalogados pelos discentes nos semestres anteriores.

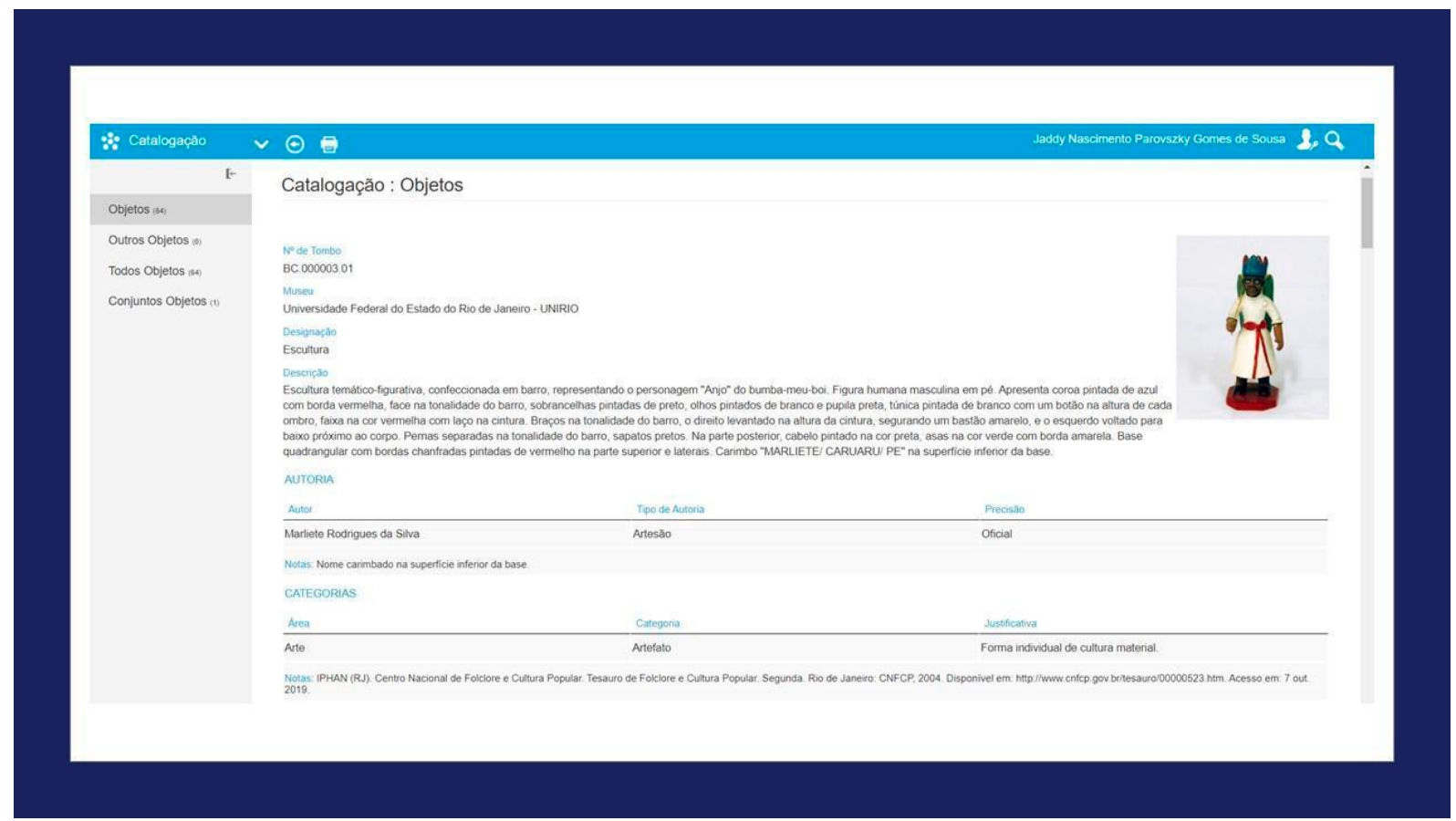

Ficha do personagem "Anjo" do conjunto Bumba-meu-boi da Biblioteca Central29. Fonte: https://unirio. inarteonline.net/.
27. Esse manual resulta de uma construção pautada em debates e contribuições estabelecidos em diversos momentos com discentes inscritos na disciplina Informação e Documentação Museológica I, a coordenadora do projeto de ensino, monitores da disciplina, museólogos e estagiários de instituições parceiras, estagiários docentes, bibliotecárias da Biblioteca Central, arquivista da Unidade de Arquivo e Protocolo Setorial da Escola de Enfermagem Alfredo Pinto e equipe Sistemas do Futuro.

28. As revisões são feitas pelos monitores (bolsistas e voluntários) e estagiários curriculares. 29. Em função do número de grupos de informações já preenchidas sobre o objeto em questão, resultando em uma ficha catalográfica extensa, priorizamos aqui apenas a imagem dos cinco campos de identificação do objeto, a saber: número de tombo, museu, designação, título e descrição, e os dois primeiros grupos de informação (autor e área). Outros grupos de informação estão preenchidos nessa ficha com informações intrínsecas e extrínsecas. 


\subsection{Reflexões, desafios e perspectivas de documentação das coleções visitáveis}

A partir do uso do sistema In Arte Online no processo de capacitação dos discentes do curso de Museologia durante as aulas práticas da disciplina, foi despertada na equipe integrante do projeto de ensino vinculado ao NUGEP o desejo de avançar no processo de reconhecimento, identificação e pesquisa dessas coleções, possibilitando, dessa forma, conhecer o contexto e a história desses objetos. A apresentação dos resultados do projeto também tem motivado a Biblioteca Central, que responde pela guarda da coleção, em conjunto com o NUGEP, a buscar estratégias para, a médio prazo, estruturar as ações de preservação de suas coleções visitáveis. Portanto, entende-se que o ensino das práticas de documentação tem atuado como um motivador, possibilitando que a própria universidade amplie o reconhecimento desses objetos como bens culturais. Dessa forma, uma ação iniciada no âmbito do eixo de ensino pode, a curto ou médio prazo, contribuir tanto para a definição de diretrizes da universidade sobre políticas de gestão do patrimônio cultural e da informação referente a ele, quanto para a transparência de suas atividades relativas a esses bens, demonstrando controle, responsabilidade e responsividade - categorias importantes da accountability na administração pública.

Ainda que muitos avanços de pesquisa tenham sido realizados, existem desafios a serem vencidos, como a dificuldade de conseguir levantar dados sobre o histórico do objeto dentro da própria instituição no que tange à cronologia dos eventos relativos ao objeto, que perpassa desde a data exata de entrada (aquisição pela instituição) até os paralelos com outras coleções. Em contraponto, por meio da parceria com o CNFCP, um dos maiores centros de pesquisa e guarda de objetos de cultura popular do país, tem sido possível aumentar a qualificação de dados sobre o universo de produção e significados locais dos objetos catalogados - fato que tem contribuído significativamente para a formação de alunos sobre o universo da cultura popular brasileira.

Outro desafio relevante é estimular um maior (re)conhecimento das coleções entre a comunidade acadêmica ${ }^{30}$ (para além do curso de museologia) e a divulgação das informações e coleções para além dos muros da

30 Docentes, discentes e técnicos administrativos. 
universidade, trazendo à tona a função social de divulgação e disseminação do conhecimento da universidade. As ações realizadas também fazem refletir sobre a importância da normalização e a complexidade de se pensar em vocabulários controlados, que possam atender aos critérios da tipologia de objetos de cultura popular e que dialoguem com outras instituições de guarda de bens culturais. Nesse sentido, a perspectiva futura, que integra os projetos de ensino, pesquisa e extensão vinculados ao NUGEP, é de ampliar o diálogo com profissionais de outras instituições de guarda de objetos associados aos conhecimentos tradicionais e populares localizadas no estado do Rio de Janeiro, com a finalidade de criar redes de integração, colaboração e cooperação sobre gestão e documentação dessas coleções, bem como a formação de um grupo de trabalho para debater e elaborar um vocabulário controlado que atenda às coleções de cultura popular.

\section{CONSIDERAÇÕES FINAIS}

As coleções universitárias têm suas origens na formação dos centros universitários, a partir de doações e práticas de ensino e pesquisa, e refletem a trajetória da própria universidade. Além disso, são consideradas unidades da universidade que adquirem, conservam, pesquisam e expõem, seja de forma limitada ou não, seus bens culturais, com fins de educação e estudo. As referências culturais sob a guarda da UNIRIO podem ser caracterizadas como coleção visitável, visto que a universidade possui bens culturais em suas unidades organizacionais que são conservados, pesquisados e expostos, permanente ou esporadicamente.

Vale ressaltar a importância de uma documentação efetiva dos objetos, possibilitando assim o reconhecimento e a identificação dessas coleções universitárias pela comunidade acadêmica, com o objetivo de promover políticas de gestão dos bens culturais.

Para que essa documentação seja efetiva, é necessária uma pesquisa mais ampla, especialmente sobre as informações extrínsecas e documentação retrospectiva, que tenha como base a consulta a outras instituições, além da gestão da informação integrada e cooperativa entre museus, bibliotecas, arquivos e outras instituições/indivíduos que contribuam para enriquecer as informações sobre as coleções.

Como demonstrado ao longo deste artigo, as ações acadêmicas de 
catalogação, potencializadas pelo uso do software de gestão de coleções, contribuem para a formação teórico-prática dos futuros profissionais de museologia, além de promover a inclusão tecnológica dos discentes.

As ações colaboram ainda para a articulação de projetos de ensino, pesquisa e extensão idealizados pelo NUGEP e pelo GEMCTAS, bem como identificam e catalogam os bens culturais sob tutela da própria universidade, contribuindo para o processo institucional de identificação e (re) conhecimento das coleções institucionais.

\section{REFERÊNCIAS}

ALMEIDA, Adriana Mortara. Museus e Coleções Universitários: por que museus de arte na Universidade de São Paulo?. 2001. Tese (Doutorado em Ciências da Informação e Documentação) - Escola de Comunicações e Artes, Universidade de São Paulo. São Paulo, 2001. Disponível em: https://teses.usp.br/teses/disponiveis/27/27143/tde-10092003-160231/pt-br. php. Acesso em: 10 jun. 2020.

ALMEIDA, Maria Christina Barbosa de. Bibliotecas, Arquivos e Museus: convergências. Revista Conhecimento em Ação, Rio de Janeiro, v. 1, n. 1, p. 1162-185, jan./jun. 2016. Disponível em: https://revistas.ufrj.br/index.php/rca/article/view/2737/2807. Acesso em: 13 jul. 2020.

APPADURAI, Arjun. Mercadorias e a política de valor. In: APPADURAI, Arjun. A vida social das coisas: as mercadorias sob uma perspectiva cultural. Niterói: EdUFF, 2008. p. 15-88. Disponível em: https://www.academia.edu/36426110/A_VIDA_SOCIAL_DAS_COISAS_As_ MERCADORIAS_SOB_UMA_PERSPECTIVACULTURAL_at_BULLET_Arjun_Appadurai. Acesso em: 22 jun. 2020.

AUGUSTIN, Raquel França Garcia; BARBOSA, Cátia Rodrigues. Políticas de Gestão de Acervos: possíveis fontes de informação para tomada de decisão nos museus. Perspectivas em Gestão \& Conhecimento, João Pessoa, v. 8, n.1, p. 134-154, jan./abr. 2018. DOI: 10.21714/2236-417X2018v8n1p134. Disponível em: https://periodicos.ufpb.br/ojs2/index.php/pgc/ article/view/35036. Acesso em: 15 jul. 2020.

BIBLIOTECA CENTRAL - UNIRIO. Acervos especiais. Disponível em: http://www.unirio.br/ bibliotecacentral/acervos-especiais-1. Acesso em: 17 jun. 2020.

BRASIL. Decreto Federal no. 8.124, de 17 de outubro de 2013. Regulamenta dispositivos da Lei no. 11.904, de 14 de janeiro de 2009, que cria o Instituto Brasileiro de Museus - IBRAM. Disponível em: http:// www.planalto.gov.br/ccivil_03/_Ato2011-2014/2013/Decreto/D8124.htm. Acesso em: 12 jun. 2020.

BRASIL. Resolução Normativa no. o2, de 29 de agosto de 2014. Estabelece os elementos de descrição das informações sobre o acervo museológico, bibliográfico e arquivístico que devem ser declarados no Inventário Nacional dos Bens Culturais Musealizados, em consonância com o Decreto no. 8.124, de 17 de outubro de 2013. Disponível em: https://www.museus.gov.br/wpcontent/uploads/2014/o9/ResolucaoNormativa2_INBCM.pdf. Acesso em: 13 nov. 2020.

CERAVOLO, Suely Moraes; Tálamo, Maria de Fátima. Os Museus e a Representação do Conhecimento: uma retrospectiva sobre a documentação em museus e o processamento da informação. In: VIII Encontro Nacional de Pesquisa em Ciência da Informação, 2007, Salvador. Anais do VIII Enancib. Salvador: UFBA, 2007. Disponível em: http://repositorios.questoesemrede.uff.br/ repositorios/bitstream/handle/123456789/143/GT2--012.pdf?sequence=1. Acesso em: 22 jun. 2020. 
CLIFFORD, James. Colecionando Arte e Cultura. Revista do Patrimônio Histórico e Artístico, Rio de Janeiro, n. 23, p. 69-89, 1994. Disponível em: http://docvirt.com/Hotpage/Hotpage.aspx? bib=RevIPHAN\&pagfis=8342\&url=http://docvirt.com/docreader.net\#. Acesso em: 9 jun. 2020.

COLLECTIONS TRUST. Spectrum 4.o: o padrão para gestão de coleções de museus do Reino Unido. São Paulo: Secretaria de Estado de Cultura de São Paulo; Associação de Amigos do Museu do Café; Pinacoteca do Estado de São Paulo, 2014. Disponível em: https://issuu.com/ sisem-sp/docs/spectrum_pt_net. Acesso em: 12 jul. 2020.

DESVALLÉES, André; MAIRESSE, François (Ed.). Conceitos-chave de Museologia. São Paulo: Comitê Brasileiro do Conselho Internacional de Museus, 2013. Disponível em: http://www.Icom.org. br/wp-content/uploads/2014/o3/PDF_Conceitos-Chave-de-Museologia.pdf. Acesso em: 12 jun. 2020.

FERREZ, Helena Dodd. Documentação museológica: teoria para uma boa prática. In: Fórum Nordestino de Museu, 4. Recife: IBPC/Fundação Joaquim Nabuco, 1991. Disponível em: https:// meumuseu.files.wordpress.com/2011/o1/documentac3a7c3a3o-museolc3b3gica-helena-doddferrez.doc. Acesso em: 17 jun. 2020.

GIL, Fernando Bragança. Museus Universitários: sua especificidade no âmbito da Museologia. In: SEMEDO, Alice (Coord.). Coleções de Ciências Físicas e Tecnológicas em museus universitários: homenagem a Fernando Bragança Gil. Porto: Universidade do Porto; Faculdade de Letras; Departamento de Ciências e Técnicas do Patrimônio, 2005. Disponível em: https:// ler.letras.up.pt/uploads/ficheiros/7644.pdf. Acesso em: 11 jun. 2020.

GONÇALVES, José Reginaldo Santos. Antropologia dos objetos: coleções, museus e patrimônios. Rio de Janeiro: Ibram, 2007. (Museu, memória e cidadania). Disponível em: https://edisciplinas.usp.br/pluginfile.php/4697385/mod_resource/content/1/

GON\%C3\%87ALVES.\%2oantropologia_dos_objetos_V41.pdf. Acesso em: 9 jun. 2020.

INTERNATIONAL COUNCIL OF MUSEUMS. Declaração de princípios de documentação em museus e diretrizes internacionais de informação sobre objetos de museus: categorias de informação do Comitê Internacional de Documentação (CIDOC - Icom). São Paulo: Secretaria de Estado de Cultura de São Paulo; Associação de Amigos do Museu do Café; Pinacoteca do Estado de São Paulo, 2014. Disponível em: https://issuu.com/sisem-sp/docs/cidoc_guidelines. Acesso em: 12 jul. 2020.

INTERNATIONAL COUNCIL OF MUSEUMS. Museum Definitions. Disponível em: https:// Icom.museum/en/resources/standards-guidelines/museum-definition/. Acesso em: 15 jun. 2020.

KOPYTOFF, Igor. A biografia cultural das coisas: a mercantilização como processo. In: APPADURAI, Arjun. A vida social das coisas: as mercadorias sob uma perspectiva cultural. Niterói: EdUFF, 2008, p. 89-142. Disponível em: https://www.academia.edu/36426110/A_VIDA_ SOCIAL_DAS_COISAS_As_MERCADORIAS_SOB_UMA_PERSPECTIVACULTURAL_at_ BULLET_Arjun_Appadurai. Acesso em: 22 jun. 2020.

LIMA, Diana Farjalla Correia. Documentação em Museus e Histórico de Propriedade (Provenance): restituição de obras de arte espoliadas pelos nazistas. In: XI Encontro Nacional de Pesquisa em Ciência da Informação, 2010, Rio de Janeiro. Anais do XI Enancib. Rio de Janeiro: UNIRIO, 2010. Disponível em: http://repositorios.questoesemrede.uff.br/repositorios/ bitstream/handle/123456789/1191/Documenta\%C3\%A7\%C3\%A30\%2O-\%2oLima.pdf?sequence=1. Acesso em: 17 jun. 2020.

LOUREIRO, Maria Lúcia de Niemeyer Matheus; LOUREIRO, José Mauro Matheus. Documento e musealização: entretecendo conceitos. Midas: Museus e Estudos Interdisciplinares, Portugal, v. 1, 2013. DOI: 10.4000/midas.78. 
LOURENÇO, Marta C. Between two worlds: the distinct nature and contemporary significance of university museums and collections in Europe. 2005. Tese (Doutorado em Museologia e História da Tecnologia) - École doctorale technologique et professionnelle, Conservatoire national des arts et métiers, Paris, 2005. Disponível em: https://webpages.ciencias.ulisboa. pt/ mclourenco/chapters/MCL2005.pdf. Acesso em: 11 jun. 2020.

MATOS, Alexandre. Normalização de procedimentos nas colecções museológicas. In: Seminário Internacional de Investigação em Museologia dos Países de Língua Portuguesa e Espanhola, n. I, 2009, Porto. Actas do I Seminário Internacional de Investigação em Museologia dos Países de Língua Portuguesa e Espanhola. Porto: Universidade do Porto; Faculdade de Letras; Departamento de Ciências e Técnicas do Património, 2010. Disponível em: https://ler. letras.up.pt/uploads/ficheiros/8620.pdf. Acesso em: 15 jul. 2020.

MENDONÇA, Lúcia Glicério. Museus universitários: de legisladores do saber a intérpretes de cultural. In: Seminário Internacional "O Futuro dos Museus Universitários em Perspetiva", 2013, Porto. Atas do Seminário Internacional o Futuro dos Museus Universitários em Perspectiva. Porto: Universidade do Porto; Faculdade de Letras; Departamento de Ciências e Técnicas do Património, 2014. Disponível em: https://ler.letras.up.pt/uploads/ficheiros/12476. pdf. Acesso em: 11 jun. 2020.

NOVAES, Mariana Gonzalez Leandro. Patrimônio científico nas universidades brasileiras: políticas de preservação e gestão das coleções não vinculadas a museus. 2018. Tese (Doutorado em Museologia e Patrimônio - Programa de Pós-Graduação em Museologia e Patrimônio, Universidade Federal do Estado do Rio de Janeiro; Museu de Astronomia e Ciências Afins, 2018. Disponível em: http://www.unirio.br/ppg-pmus/mariana_novaes.pdf. Acesso em: 3 jul. 2020.

PERNAMBUCO DE OLIVEIRA. In: Enciclopédia Itaú Cultural. São Paulo: Itaú Cultural, 2017. Disponível em: http://enciclopedia.itaucultural.org.br/pessoa400698/pernambuco-de-oliveira. Acesso em: 17 jun. 2020.

RIBEIRO, Emanuela Sousa; SEGANTINI, Verona Campos; GRANATO, Marcus. Museus e patrimônio cultural universitário: discutindo conceitos e promovendo parcerias e articulações. In: Seminário Brasileiro de Museologia, n. III, 2017, Belém. Museologia e suas interfaces críticas: museu, sociedade e os patrimônios. Recife: UFPE, 2019. Disponível em: https://orbi.uliege.be/bitstream/2268/239341/3/2019\%20 E-BOOK\%2oREDE\%2oMUSEOLOGIA.pdf. Acesso em: 22 jun. 2020.

SEMEDO, Alice. Políticas de gestão de coleções (Parte 1). Revista da Faculdade de Letras, Ciências e Técnicas do Património, Portugal, série I, vol. IV, p. 305-322, 2005. Disponível em: https://ler.letras.up.pt/uploads/ficheiros/4949.pdf. Acesso em: 17 jun. 2020.

SERÔDIO, Conceição. Contributos para uma gestão integrada dos acervos nos museus portugueses. Midas: Museus e Estudos Interdisciplinares, Portugal, n. 9, 11p., 2018. Disponível em: https://journals.openedition.org/midas/1371. Acesso em: 15 jul. 2020. DOI: 10.400o/midas.1371.

SOUZA FILHO, Carlos Frederico Marés de. Proteção jurídica dos bens culturais. São Paulo: Revista dos Tribunais, 2005.

TANUS, Gabrielle F.S.C. A trajetória do ensino da Museologia no Brasil. Revista Museologia \& Interdisciplinaridade, Brasília, v.2, n.3, p. 76-88, maio/jun. 2013. Disponível em: http://periodicos. unb.br/index.php/museologia/article/download/16688/14968/. Acesso em: 15 jun. 2020.

THORNES, Robin; DORRELL, Peter; LIE, Henry. Introduction to Object ID: guidelines for making records that describe art, antiques, and antiquities. Los Angeles: Getty Information Institute, 1999. Disponível em: http://d2aohiyo3d3idm.cloudfront.net/publications/ virtuallibrary/o892365722.pdf. Acesso em: 13 nov. 2020.

\section{(cc) $\mathrm{EY}-\mathrm{No}-\mathrm{BA}$}

